Distribution of 251 cases of acute myocardial infarction ( $A M I)$ and 475 controls and odds ratios (with $95 \%$ confidence intervals, $C I$ ) according to oral contraceptive (OC) use. Italy, 1983-92.

\begin{tabular}{|c|c|c|c|c|}
\hline & \multirow{2}{*}{$\frac{A M I}{\text { No }(\%)}$} & \multirow{2}{*}{$\frac{\text { Controls }}{\text { No }(\%)}$} & \multicolumn{2}{|c|}{ Odds ratios $*(95 \% C I)$} \\
\hline & & & $R R 1$ & $R R 2$ \\
\hline $\begin{array}{l}\text { OC use: } \\
\text { Never users } \\
\text { Ever users }\end{array}$ & $\begin{array}{r}201(80 \cdot 1) \\
50(19 \cdot 9)\end{array}$ & $\begin{array}{r}423(89.1) \\
52(10.9)\end{array}$ & $\begin{array}{l}1^{\dagger} \\
2 \cdot 2(1 \cdot 4,3 \cdot 4)\end{array}$ & $\begin{array}{l}1 \dagger \\
1.7(1 \cdot 1,3 \cdot 1)\end{array}$ \\
\hline $\begin{array}{l}\text { Current users } \\
\text { Past users }\end{array}$ & $\begin{array}{c}7(2 \cdot 8) \\
43(17 \cdot 1)\end{array}$ & $\begin{array}{r}6(1 \cdot 3) \\
46(9 \cdot 7)\end{array}$ & $\begin{array}{l}2.9(0.9,9 \cdot 3) \\
2 \cdot 1(1.3,3 \cdot 4)\end{array}$ & $\begin{array}{l}2 \cdot 0(0 \cdot 6,6 \cdot 7) \\
1 \cdot 8(1 \cdot 0,3 \cdot 2)\end{array}$ \\
\hline $\begin{array}{l}\text { Duration of use: } \\
\leqslant 2 \text { years } \\
>2 \text { years }\end{array}$ & $\begin{array}{l}23(9 \cdot 2) \\
27(10 \cdot 8)\end{array}$ & $\begin{array}{l}25(5 \cdot 3) \\
27(5 \cdot 7)\end{array}$ & $\begin{array}{l}2 \cdot 1(1 \cdot 1,3 \cdot 9) \\
2 \cdot 3(1 \cdot 3,4 \cdot 0)\end{array}$ & $\begin{array}{l}2 \cdot 1(1.0,4 \cdot 4) \\
1.5(0.7,2 \cdot 9)\end{array}$ \\
\hline $\begin{array}{l}\text { Time since last use: } \\
\leqslant 2 \text { years } \\
>2 \text { years }\end{array}$ & $\begin{array}{c}8(3 \cdot 2) \\
35(13 \cdot 1)\end{array}$ & $\begin{array}{r}6(1 \cdot 3) \\
40(7 \cdot 4)\end{array}$ & $\begin{array}{l}3.5(1.2,10.5) \\
1.9(1.2,3.2)\end{array}$ & $\begin{array}{l}2.8(0.8,9.3) \\
1.7(0.9,3.0)\end{array}$ \\
\hline
\end{tabular}

* Estimates from multiple logistic regression equations including, for RR1: age in quinquennia and area of residence; for RR2: age, area of residence plus smoking habits (never smoker/exsmoker/current smoker of $<20$ cigarettes/day, $\geqslant 20$ cigarettes/day), body mass index, history of angina, diabetes, hypertension, and hyperlipidaemia.

t Reference category. genic process. An additive effect was observed for hyperlipidaemia, whereas the greatly increased risk of women reporting both oral contraceptive use and hypertension was more consistent with a multiplicative effect on the OR.
From a public health viewpoint, only about $1 \%$ of events of acute myocardial infarction in this population is attributable to oral contraceptive use, in strong contrast with the approximate $50 \%$ attributable to smoking among Italian women. ${ }^{2}$ The association between oral contraceptive use and acute myocardial infarction is now of a modest importance on a public health level in this population.

This work was conducted within the framework of the CNR (Italian National Research Council) Applied Project "Prevention and Control of Disease Factors" (Contract

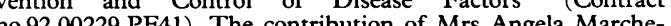
no 92.00229.PF41). The contribution of Mrs Angela Marchegiano Borgomainerio is gratefully acknowledged. The authors

thank Mrs Judy Baggott, Mrs Ivana Garimoldi, and the GA

1 Thorogood M. Oral contraceptives and cardiovascular disease: An epidemiologic overview. Pharmacoepidemiol Drug Saf 1993;2:3-16.

2 La Vecchia C, Franceschi S, Decarli A, Pampallona S, Tognoni G. Risk factors for myocardial infartion in young women. Am f Epidemiol 1987;125:832-43.

3 Breslow NE, Day NE. Statistical methods in cancer research. Vol 1. The analysis of case-control studies. Lyon: IARC Science Publications 1980;32.

4 Stampfer MJ, Willett WC, Colditz GA, Speizer FE, Hennekens $\mathrm{CH}$. A prospective study of past use of oral contraceptive agents and risk of cardiovascular diseases. contraceptive agents and risk of

5 Royal College of General Practitioners. Further analysis of mortality in oral contraceptive users. Lancet 1981;i:541-6.

\title{
The "healthy passive smoker": relationship between bronchial hyper-reactivity in school children and maternal smoking
}

\author{
R Meinert, Th Frischer, J Kuehr
}

The term 'healthy smoker effect' describes a primary process of self selection by which only healthy subjects tend to start smoking, and a secondary process of disease related attrition by which subjects with a lung disorder are likely to stop smoking. We present data from a cross sectional study on the association between maternal smoking and bronchial hyper-reactivity (BHR) in 14018 year old school children, in whom the phenomenon of "healthy passive smokers" was observed. ${ }^{1}$ Information on the children's asthma status and maternal smoking was gathered via parental questionnaires. Maternal smoking ("yes/no") was recorded for the time before pregnancy, during pregnancy, in the child's 1st year of life and the child's 8th year of life. BHR was assessed by a free running test and defined as a fall in peak expiratory flow rate $\geqslant 15 \%$ after exercise.

Results: Ninety two children $(6 \cdot 6 \%)$ had BHR. Of 162 asthmatics, $25(15.4 \%)$ had BHR. There was a positive association between BHR and maternal smoking before pregnancy, during pregnancy, and in the children's 1st year of life, but not for the children's 8th year of life (figure). In asthmatics these associations were more pronounced. A negative relationship was found in the children's 8th year of life. After pregnancy, $15 \cdot 2 \%$ (asthmatics: $20 \%$ ) of mothers of children with BHR compared with $8 \cdot 6 \%$ (asthmatics: $8 \cdot 0 \%$ ) of mothers of children without BHR began smoking. Between the child's 1st and 8th year, $7 \cdot 6 \%$ (asthmatics: $0 \%$ ) of mothers of children with BHR compared with $11 \cdot 3 \%$ (asthmatics: $11 \cdot 7 \%$ ) of mothers of children without BHR began smoking, while $7 \cdot 6 \%$ (asthmatics: $16.0 \%$ ) of mothers of responsive children stopped smoking compared with $3.4 \%$ (asthmatics: $2.9 \%$ ) of those with unaffected children. This association between BHR and changes in maternal smoking habits was significant ( $p=0.021$, Fisher's exact test) in asthmatics but not in the whole sample $(p=0 \cdot 11)$. Discussion: Our data suggest that mothers of children with BHR, especially mothers of asthmatic children, seemed less likely to take up smoking. Furthermore, the occurrence of BHR obviously stimulated mothers to quit smoking. Hence, the use of the term "healthy passive smoker" seems to be justified, although possible biases exist. We can only speculate about the true inter-relation between exposure and disease, since we do not know when a child developed BHR for the first time. Information on maternal smoking status was gathered retrospectively for an eight year period, which could cause reporting bias. Nevertheless, we think the overall impression of changes in maternal smoking habits with regard to the time course and the children's 
Total sample $(n=1401)$

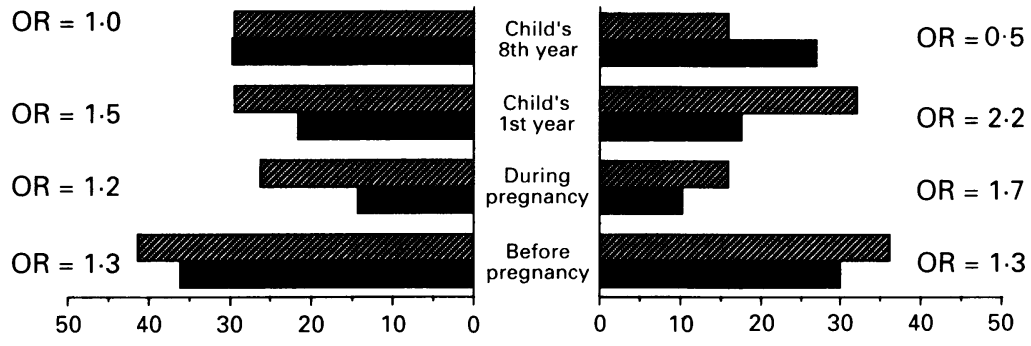

Children without BHR

Children with BHR

Proportion (\%) of mothers who smoked in relation to bronchial hyper-reactivity $(B H R)$. the relationship between current respiratory symptoms and changes in maternal smoking habits was weak (data not presented).

If there is a mutual inter-relation between exposure and disease, the analysis of the relationship between current exposure and disease can easily give misleading results. For example, not taking information on prior passive smoke exposure into account, our data would suggest that eight year old asthmatic children of currently smoking mothers have only half the risk of developing BHR, as have asthmatic children of non-smoking mothers. We conclude that in cross sectional studies investigating long term exposure there is a high risk of underestimating effects if only information on current exposure status is available. In order to assess the true exposure-disease relationship it seems important to acquire information on status of exposure at different prior points in time as well, and, if possible, on disease status at prior points in time. pecially in the group of asthmatics.

One might argue that the occurrence of respiratory symptoms associated with $\mathrm{BHR}$, rather than BHR per se, might influence maternal smoking habits. We used BHR as an outcome variable because the free running test is an objective and standardised measurement, while respiratory symptoms recorded by means of parental questionnaires are likely to be affected by reporting bias. Indeed, in our study BHR was closely associated with chronic respiratory symptoms in atopic children, ${ }^{2}$ but This work has been supported by a grant (no 0701565/5) from
the Bundesministerium für Forschung und Technologie (BMFT). The authors thank Ms G Stadler.

1 Frischer T, Kuehr J, Meinert R, Karmaus W, Barth R, Hermann-Kunz E, Urbanek R. Maternal smoking in early childhood: a risk factor for bronchial responsiveness to exercise in primary-school children. $\mathcal{f}$ Pediatr 1992; 121:17-22.

2 Frischer Th, Kühr J, Meinert R, Karmaus W, Forster J, Urbanek R. Relation between response to exercise and diurnal variability of peak expiratory flow in primary school children. Thorax 1993;48:249-53. 